\title{
A fishy business
}

\section{E. Purdom and A. Preston assess the state of fish farming and its future promise}

F ISH farming is arousing widespread interest on the basis of a variety of concepts, some of which are not valid. There is such confusion about the motives of fish farming research that it is necessary to define clearly the role that this form of animal husbandry has within the context of UK food supplies.

Throughout the world, fish farming takes many forms but there are three basic categories:

- sea ranching: fish are reared for release into the sea as juveniles, where they subsequently grow to marketable size;

- extensive production using natural productivity;

- intensive farming which relies on supplied feeds.

Sea ranching has strict limitations, being feasible only where the natural tendency of the fish is to return to the point of release when they are fully grown. Salmon and sturgeon in the United States and the Soviet Union respectively are farmed in this way. There seems little immediate prospect that private enterprise will be stimulated by the vision of a valuable investment swimming off to distant waters.

Extensive cultivation is carried out basically by warm water pond farming. It is by far the most widespread of fish farming systems on a global basis and is found in most areas where space, climate and a local market justify it. Carp (Cyprinus carpio) is the archetypal species in pond farming, but a quite spectacular growth occurred in catfish (Ictalurus punctata) farming in the southern states of the United States during the 1960s and there has been recent progress with several other species of fish in fresh and brackish waters in south-east Asia.

Pond fish farming depends upon natural productivity and, like any other form of extensive animal husbandry, benefits from pest control, the use of fertilisers and the supply of supplementary feeds. Its productivity is governed by management practices and, of course, by the natural features of the farm. Natural productivity alone is low, perhaps a few hundred kilograms per acre per year at best. Fertilisation and other water management practices can double this but big dividends come only from the use of supplementary feeds. Here is a snag: fish are not efficient users of food

C. E. Purdom and A. Preston are from the Ministry of Agriculture, Fisheries and Food's Fisheries Laboratory, Lowestoft. materials other than animal protein and fat. Occasional reference is made to the desirability, in a protein saving context, of rearing herbivorous fish. The fact that such species require over $100 \mathrm{~kg}$ of feed to make $1 \mathrm{~kg}$ of flesh, however, puts them way below the performance of farm ruminants.

Intensive farming is almost wholly artificial. Fish are held in small containers which are commonly circular tanks, linear raceways or net enclosures in tidal waters. Very high stock densities are maintained with a large flowthrough of water. At fish densities up to $100 \mathrm{~kg} \mathrm{~m}^{-3}$ all the nutritional requirements must be met in prepared feeds which must contain high levels of animal protein, $40-45 \%$ dry weight, moderately high lipid content and vitamin supplements. Such feeds are expensive, but the rationale of intensive farming is to produce high quality protein from low quality protein (quality being defined in terms of acceptability for human consumption). Feed protein is converted into fish protein with an efficiency of about $30 \%$ and intensive farming is therefore a net user of protein. The fish most commonly farmed this way are salmon and trout, in fresh or salt water, but large quantities of yellow-tail, a fully marine species, are farmed intensively in Japan.

\section{No cheap protein}

It is abundantly clear that fish farming is not a means of producing cheap protein. Whenever fish are farmed, they are high quality, high priced foods. A further view of fish farming is that it is an alternative, or a meaningful supplement, to the yield from sea fisheries. This idea is also invalid on the grounds that the two spheres of activity are of widely differing scales. UK fish landing approach one million tonnes per year: currently, fish farming contributes 2,500 tonnes per year. Assuming a ten-fold increase during the next five years, which is both worthwhile and probable, the scale of fish farming will still be totally inadequate to accommodate the fluctuations in the yield from sea fisheries, which can follow from political or management decisions or from natural causes: these may be measured in hundreds of thousands of tonnes. However, for individual species of fish, for which landings are low, for example turbot (700 tonnes UK landings in 1975) or sole (1,300 tonnes UK landings in 1975), there is some prospect of significantly

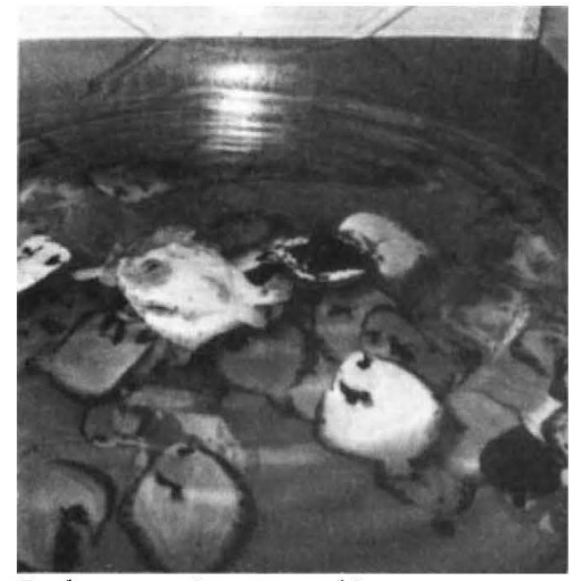

Turbot: no pigment problem

adding to supplies by farming.

Fish farming in the UK probably will be based on intensive systems for the supply of specific types of fish suitable for these systems and for which a current demand exists. The two species likely to fulfil these requirements are rainbow trout (Salmo gairdnerii), which constitutes the bulk of present farm production, and turbot (Scophthalmus maximus), which has been researched intensively over the past five years and is currently under pilot scale commercial production.

Research on plaice, sponsored by the Ministry of Agriculture, Fisheries and Food (MAFF) began in the 1950s. This species is no longer thought suitable for cultivation because it is relatively abundant around the UK, has a fairly stable population, and is not a good enough converter of food to sustain an economically viable industry. After much background research, therefore, attention was turned to sole and turbot which are prime fish of high value and in short supply. Mass rearing techniques were quickly established for sole along the lines developed for plaice, Little progress was made with ongrowing (that is, rearing hatched fish to marketable size and sexual maturity), because the hatchery-reared juvenile fish were difficult to wean onto prepared diets. The sole is a quiet feeder with nocturnal, browsing habits--the introvert of the flatfish families. Further research in MAFF laboratories was restricted to the weaning phase. Turbot was assessed first in terms of its ongrowing capabilities. It passed the test, being voracious, a good protein converter (achieving levels up to $50 \%$ ), and robust and docile towards anything it could not swallow. Growth rate is then dependent on temperature.

\section{Hatchery techniques}

Following the satisfactory outcome of these trials, using small fish collected from the beaches, efforts were made to develop a hatchery technique to raise juveniles from eggs. Plaice and sole larvae were satisfactorily grown 
on a diet of Artemia nauplii. Turbot, however, were too small initially to feed on nauplii but they could feed on natural plankton, mussel veligers and the rotifer Brachionus plicatilis, the latter being the most suitable. After a few days feeding on rotifers, turbot larvae accepted nauplii but the problems did not end there. Metamorphosed fish were reared for the first time in 1972; about 100 were produced from many thousands of eggs. Steady annual improvements in empirical techniques have since been made, and survival rates up to $25 \%$ are now feasible.

Solving the early feeding needs of the larvae, at least at an empirical level, did not remove all the obstacles to successful rearing of turbot. A number of minor problems, 'dropsy' in young larvae, a later lack of swimbladder development and atypical pigment formation at metamorphosis, mostly diminished with increasing experience. A major problem, however, was that, unlike plaice and sole, turbot larvae were not satisfied for long on a diet of Artemia nauplii. Progressively larger Artemia, grown on unicellular algae, were required by the fish as they grew larger themselves. A weaning process was developed whereby the larvae were switched to prepared foods by using specially designed weaning tanks which kept inanimate food particles moving but did not sweep the fish down the overflow. Rearing turbot larvae is now almost routine but it still requires sophisticated laboratory facilities and further research is needed to clarify scientific aspects and to simplify systems for commercial use.

Sole have similarly been weaned from Artemia to prepared diets but for rather different reasons. Earlier work with sole relied on a succession of live foods but these are not suitable for commercial use and they not only delay the problem of weaning but also intensify it: the luxury of live foods appeared to be habit forming. A clear demonstration that sole is suitable for domestication still remains to be made.

\section{Coping with seasonal spawners}

A problem with turbot, as with most fish, is that spawning is seasonal. This restricts management options in commercial farming and it also limits the pace at which research can proceed. Most seasonal spawners have light or temperature regulated hormonal clocks and in theory can be persuaded to spawn out of season by the correct manipulation of whatever parameter is appropriate. On the basis of successful work with dab, trials were set up to influence the spawning pattern of turbot, which normally spawns in midsummer. Spawning has been brought forward to March in one series and further trials are aimed at delaying spawning until early winter. The indoor work of hatching and larval rearing could then be completed by spring when the juvenile fish could make use of increasing temperatures outdoors.

Work with flatfish has been aimed at creating a new form of fish farming. Recent commercial investment in this area is a measure of its success and has introduced the provision of advice and assistance to industry through research and development programmes. The growth of trout farming led to a similar demand for R\&D programmes and, after a recent review, it was planned that all the MAFF's fishing farming research, except work on infectious diseases, should be located at the Fisheries Laboratory, Lowestoft.

The trout research programme is divided into water management, genetics and feeding strategies. Water is clearly a limiting factor in trout farming and in simple systems about 20,000 gallons are used for each pound of fish produced. But the first limiting factor is oxygen. Water-saving systems employing oxygen or air are under development by industry. Removing the limitation of oxygen increases the levels of carbon dioxide, ammonia, nitrite and nitrate. Limited research on the effects of these and other water quality factors is planned but the principal MAFF investigation will be on the use of sea water for farming trout. This offers immediate scope for large scale increases in production.

Rainbow trout are not naturally anadromous but are successfully reared in sea water in some parts of the world. Smolting does not occur, as in salmon and migratory trout, but the ability of rainbow trout to withstand transfer to sea water increases with their size. Preliminary trials suggest that $30-90 \mathrm{~g}$ is the range over which fish may be acclimatised but there is evidence that

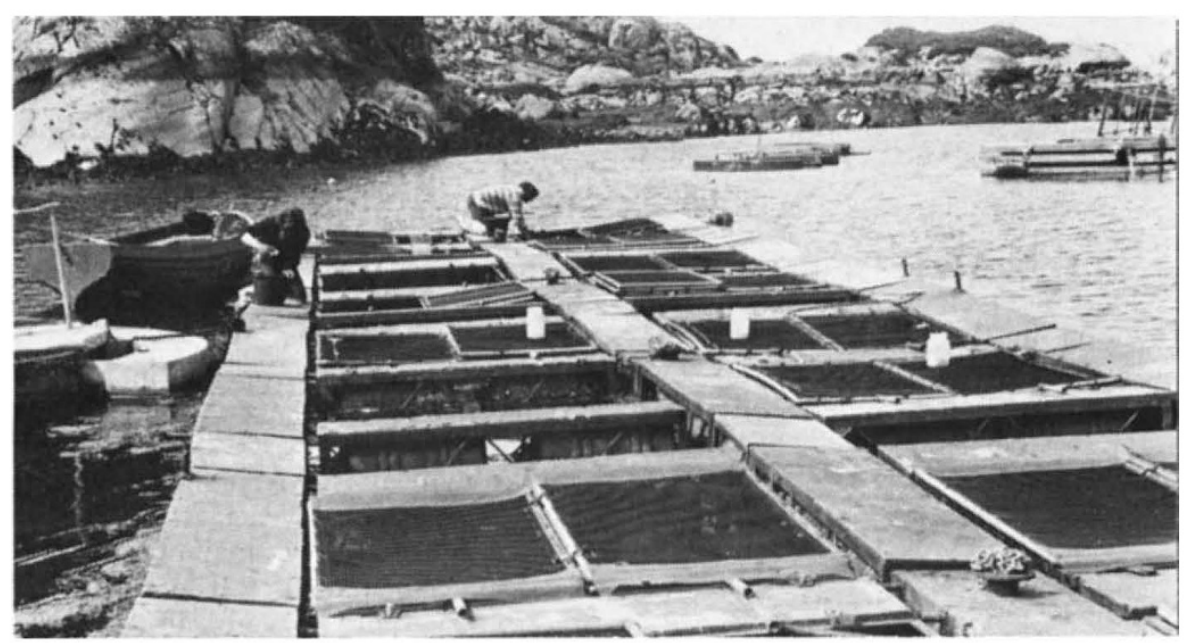

Cages of plaice and turbot in the North Channel age may be important and that domesticated strains vary in their tolerance of sea water. Clearly it is important to establish the earliest possible transfer to sea water where portion-sized fish of around $250 \mathrm{~g}$ are produced, but for larger fish, for which there is a growing market, the need is not so marked.

The genetic programme is based on the fact that several individual strains of rainbow trout already exist. A number of these strains have been imported with the objective of developing disease-free broodstock for subsequent trials both of the characteristics of the strains themselves and of cross-breeds. Electrophoretic analysis of enzyme polymorphisms suggests that some of the strains are inbred.

Strains differ in the time at which they spawn and it may be possible with trout to supply eggs throughout the year without recourse to environmental manipulation-more difficult for trout than for turbot on account of their relatively low fecundity and the need for large numbers of broodstock. Other genetic aims include selection for larger egg size and for late maturity.

Feeding is by far the most cost sensitive area of trout farming but despite a long history of domestication, there is little standardisation of feedUK is to use pelleted feeds but in other countries, much reliance is placed on the use of cheap trash fish, particularly in sea water culture. Routine use is made of such materials within Ministry work but detailed nutritional and logistic assessment remains to be made. industry has no other commitment but to operate in a cost-effective way. MAFF research has established a basis for turbot farming and continues to explore this and rainbow trout farming in order to supply industry with scientific advice. ing strategies. Current practice in the

Fish farming as a food producing 